\title{
Chemical Degradation and Color Changes of Paint Protective Coatings Used in Solar Glass Mirrors
}

\author{
Mohamed Guerguer ${ }^{1, *}$, Sanae Naamane ${ }^{2} \mathbb{D}$, Zineb Edfouf ${ }^{3}(\mathbb{D})$, Olivier Raccurt ${ }^{4}$ and Hassan Bouaouine ${ }^{1,5}$ \\ 1 Mechanical Department, Ecole Mohammadia d'Ingénieurs (EMI), Mohammed V Agdal University, \\ Rabat 10080, Morocco; H.Bouaouine@gmail.com \\ 2 Moroccan Foundation for Advanced Science, Innovation and Research (MAScIR), Rabat 10100, Morocco; \\ s.naamane@mascir.com \\ 3 Faculty of Sciences, Mohamed V University, Rabat 10080, Morocco; zedfouf@hotmail.com \\ 4 Thermal, Biomass and Hydrogen Department, University Grenoble Alpes-CEA, LITEN, \\ F-38054 Grenoble, France; olivier.raccurt@cea.fr \\ 5 Material Science Department, Ecole Normale Supérieure des Mines de Rabat (ENSMR), av. Haj Ahmed \\ Cherkaoui, Rabat 10000, Morocco \\ * Correspondence: guerguer.med@gmail.com
}

Citation: Guerguer, M.; Naamane, S.; Edfouf, Z.; Raccurt, O.; Bouaouine, $\mathrm{H}$ Chemical Degradation and Color Changes of Paint Protective Coatings Used in Solar Glass Mirrors. Coatings 2021, 11, 476. https://doi.org/ 10.3390/coatings11040476

Academic Editor: Pier Luigi Bonora

Received: 1 January 2021

Accepted: 6 April 2021

Published: 19 April 2021

Publisher's Note: MDPI stays neutral with regard to jurisdictional claims in published maps and institutional affiliations.

Copyright: (c) 2021 by the authors. Licensee MDPI, Basel, Switzerland. This article is an open access article distributed under the terms and conditions of the Creative Commons Attribution (CC BY) license (https:// creativecommons.org/licenses/by/ $4.0 /)$.
Abstract: This paper reports a study of the influence of outdoor natural aging on paint coatings applied to the back of three commercial solar glass mirrors (A1, C2, and D2) under two different exposure environments (marine and desert) in Morocco for a period of about three years. The aging assessment was carried out through colorimetric measurements and FTIR-ATR (Attenuated total reflection-Fourier transform infrared) analyses of the top coat paints. The obtained results demonstrate that the tested coating system had a high resistance at the desert site. Under the desert environment, no obvious changes to the coating occurred after 350 days. However, at the marine site, some color changes were detected, and the coating got yellow and more matte, especially for mirror A1. FTIR-ATR analyses have indicated many modifications in the intensity of many bonds of infrared spectra especially for paint of this mirror type (A1). This chemical degradation is not only due to UV degradation but also related to many factors, such as humidity, salinity, and rainfall. This finding was concluded after the faster degradation observed on samples exposed at the marine site. The present study confirms the need to use different exposure environments for testing the limits of new protective systems for solar glass mirrors rather than using only the real service conditions. Finally, accelerated tests are necessary for understanding the effect of each degrading parameter and their results should be compared to outdoor tests data for a complete analysis of coatings durability.

Keywords: paint aging; solar mirrors; chemical degradation; color change

\section{Introduction}

Today, concentrating solar power (CSP) is became the major source of renewable electricity generation in Morocco. The country has implemented the world's largest concentrated solar farm in Ouarzazate city that will provide 580 megawatts and save the planet from over 760,000 tons of carbon emissions [1]. Morocco has one of the best solar regimes in the world with an average direct insulation of $2200 \mathrm{kWh} \cdot \mathrm{m}^{-2} \cdot \mathrm{year}^{-1}$ and a wide range of climates (desert and arid areas). It has one of most ambitious energy targets in the world. The goal is for $52 \%$ of its power to come from renewable sources (20\% solar, $20 \%$ wind, $12 \%$ hydro) by 2030 [1-3]. The country is well on track to hit its target, too, with $35 \%$ of its energy being already renewable thanks to sites such as Noor Ouarzazate, Noor Midelt and Noor Boujdour.

Moroccan research institutions must support these industrial challenges through the launch of several research programs in order to contribute to CSP technology development, market deployment, and energy partnerships for sustainable, reliable, efficient, and costcompetitive concentrating solar technologies. Moreover, those research programs should 
provide information and recommendations to policy-makers. Within this context, MAScIR (Moroccan Foundation for Advanced Science, Innovation and Research) has launched in collaboration with CEA (Commissariat à l'Energie Atomique et aux Énergies Alternatives, France) a study that has as main objective testing the durability of solar mirrors used for CSP plants under different Moroccan weather conditions [4-10].

In the last decade, scientists have been endeavoring to develop new materials for solar technologies with ideal performances for CSP plants [11-17]. The conducted studies have yielded important technical improvements which help to increase the overall efficiency of CSP technologies. However, more improvements are needed in order to achieve a large portion of the world's demand for electricity. Reflectors (mirrors) are the major components of the solar field in all CSP technologies (parabolic trough, solar power tower, linear Fresnel, and dish Stirling). Since the solar field accounts for nearly half the total plant construction cost, optical performances and durability of reflectors are paramount. The reflector cost for all CSP technologies represents about $30 \%$ of the collector cost. Mirrors reflect and focus the sunlight onto a receiver to create high-temperature steam to drive conventional steam turbines. Thus, optical performance of mirrors used should ensure high efficiency and stability over the lifetime of the CSP plant, which is required to be at least 25 years [11].

Monolithic glass mirrors are the main technology used as solar reflectors in CSP power plants. This technology consists of a $1-4 \mathrm{~mm}$ low iron glass layer coated with a reflective silver layer which is protected with a layer of copper and a protective paint system composed by several coatings on the mirrors back. The role of these coatings is to protect the metallic layers against corrosion by creating a barrier to the diffusion of contaminants present in the atmosphere to the metallic layers [18]. The paint material used in monolithic mirrors consists of two (thin mirrors) or three (thick mirrors) protective coatings. The primer and intermediate layers contain zinc, magnesium, calcium, barium, sulfur, iron, silicon, and lead in oxide, sulphate, or borate states. The prime layer acts as a corrosion preventer and the intermediate layer as a diffusion barrier. The top coat contains a polymeric binder and stabilizers, such as $\mathrm{TiO}_{2}$ (rutile) and $\mathrm{ZnO}$, which prevent $\mathrm{UV}$ radiation from reaching the intermediate paint layer [15]. Paint coatings for exterior applications are made up of four compound types: Binder, fillers, solvents, and additives [19-21]. The binder is the main part of paint coatings. The binder is mainly responsible for adhesion with the substrate. In most cases, it is a macromolecular organic compound [20,21]. Binders for mirrored paint coatings are commonly based on poly acrylates, melamine, urethane, and epoxy bases. Fillers influence the physical properties of the coating, its appearance and its resistance to corrosion. The main used pigments are titanium dioxide $\left(\mathrm{TiO}_{2}\right)$ and iron oxides $\left(\mathrm{FeO}\right.$ or $\left.\mathrm{Fe}_{2} \mathrm{O}_{3}\right)$. The first is a white pigment used in exterior coatings and provides good UV protection thanks to its high refractive index. The second is found in a wide variety of forms, has a red color, and can be contained in both primer and top layers. Other inorganic pigments are used to modify paint density, permeability, flow, and hardness. The three most common are calcium carbonates $\left(\mathrm{CaCO}_{3}\right)$, silicates like talc $\left(\mathrm{Mg}_{3} \mathrm{Si}_{4} \mathrm{O}_{10}(\mathrm{OH})_{2}\right)$, and barium sulfate $\left(\mathrm{BaSO}_{4}\right)$. Solvents, usually organic, are used to modulate the viscosity of the binder in order to apply more easily the coating to the substrate with conventional methods. Solvents evaporate when the coating crosslinks [19]. Additives are chemical compounds that are added in small amounts to modify the properties of the paint systems.

Many coating systems were developed and tested by solar mirror manufacturers in order to provide new solar reflectors with less paint layer thickness and enhanced lifetime [22].

Paint coatings, as well as other layers composed monolithic glass mirrors, are subject to physico-chemical degradation when exposed to natural environments. The most common chemical mechanisms leading to degradation of coatings are photochemical degradation and hydrolysis resulting from UV radiation, air, and water [20,21]. These processes can sometimes work together, such that the overall rate of degradation is greater than the sum of the individual components. Those degradation mechanisms are thermally-activated processes, whose rate increases with exposure temperature. Hydrolytic degradation maybe 
enhanced by exposure to acid, from acid rain or from acids that reside in the coating, for example, acid catalysts used to enhance the rate of cross-linking. Other atmospheric degrading factors, such as ozone and oxides of nitrogen and sulfur, play a minor role compared to photo-oxidation and hydrolysis [20,21].

The severity of degradation is related to the aggressivity of exposure environments. The degradation of paint films alters their protective role and causes corrosion of reflective layer and, therefore, decreases the lifetime of solar mirrors. Depending to their application, several factors could influence the durability of paints, such as temperature, solar irradiation, humidity, pollution, and moisture [23,24]. The resistance of paint coatings to environmental stress is usually evaluated in term of changes in physical properties or appearance. Thus, paint system weatherability is assessed in terms of embrittlement and cracking, loss of adhesion, loss of gloss, and color change, while corrosion protection is assessed in terms of paint blistering, loss of paint adhesion, and pitting or perforation of the substrate.

Accelerated tests, such as salt-spray test, wet/dry cycle corrosion tests, and a combination of corrosion/weathering tests, and wet/dry corrosion cycles with ultraviolet (UV) condensation cycles, allow evaluating paint resistance under extreme conditions and permit understanding of the effect of each degrading parameter on paint behavior $[20,25]$. These tests are based on correlation of the physical changes induced by the selected test exposure conditions with those observed under some standard conditions (e.g., a defined course of natural exposure). However, analyzing the synergic effect of degradations resulting from all/or some combinations of the degrading factors (temperature, UV irradiation, humidity, salinity, pollution, and moisture) is only possible by using outdoor exposure tests. To achieve a better understanding of the real behavior of paint coatings, indoor tests results should be compared and validated by outdoor testing data.

This paper presents the results of outdoor exposure tests of paint coating applied to the backs of three commercial solar glass mirrors exposed under two different climates (marine and desert) in Morocco.

\section{Materials and Methods}

\subsection{Paints}

Three types of commercial monolithic silvered-glass from manufacturers 1 and 2 with different glass thicknesses (two thick mirrors (A1 and C2) and one thin sample (D2)) have been subject to weathering tests on two different exposure sites in Morocco (marine and desert sites). The description and the detailed composition of each mirror have been given in a previous publication [6]. Tested mirrors were cut from larger mirrors supplied by manufacturers with at least one protected edge. Samples were tested as received without any initial laboratory preparations. The initial colorimetric $L^{*} a^{*} b^{*} G$ and $X Y Z$ values of the outer paint coating of each mirror are given in Table 1.

Table 1. Initial colorimetric values of tested paints measured at both color spaces (CIE Lab and XYZ).

\begin{tabular}{cccccccc}
\hline \multirow{2}{*}{ Sample } & \multicolumn{3}{c}{ CIE Lab Space } & \multicolumn{3}{c}{ XYZ Space } \\
\cline { 2 - 8 } & $\boldsymbol{L}^{*}$ & $\boldsymbol{a}^{*}$ & $\boldsymbol{b}^{*}$ & $\boldsymbol{G}$ & $\boldsymbol{X}$ & $\boldsymbol{Y}$ & $\boldsymbol{Z}$ \\
\hline A1 & 93.50 & -1.30 & -0.90 & 38 & 79.50 & 84.30 & 92.90 \\
C2 & 94.59 & -0.85 & -0.04 & 43 & 81.93 & 86.66 & 94.41 \\
D2 & 95.49 & -0.98 & 0.47 & 46 & 83.87 & 88.78 & 95.96 \\
\hline
\end{tabular}

The paints applied on monolithic mirrors tested in this study use organic binders composed of a mixture of alkyd resin, acrylic copolymer, styrene, and a melamine resin (HMMM). The pigments composing these paints can be found in Table 2 according to XRD analysis conducted on the un-exposed samples of each mirror type [6]. 
Table 2. Description of paint systems used in each tested mirror.

\begin{tabular}{cccc}
\hline Mirror & Paint Coatings System & Paint Thickness $(\boldsymbol{\mu m})$ & Pigments \\
\hline $\mathrm{A} 1$ & 3 & 90 & $\mathrm{TiO}_{2}, \mathrm{BaSO}_{4}$ and $\mathrm{Mg}_{3} \mathrm{Si}_{4} \mathrm{O}_{10}$ \\
$\mathrm{C} 2$ & 3 & 90 & $\mathrm{TiO}_{2}, \mathrm{BaSO}_{4}$, and $\mathrm{Mg}_{3} \mathrm{Si}_{4} \mathrm{O}_{10}$ \\
$\mathrm{D} 2$ & 2 & 64 & $\mathrm{TiO}_{2}, \mathrm{BaSO}_{4}$, and $\mathrm{Mg}_{3} \mathrm{Si}_{4} \mathrm{O}_{10}$ \\
\hline
\end{tabular}

\subsection{Outdoor Exposure Tests}

In this study, paints were subject to natural weathering using two different outdoor testing sites in Morocco which are located respectively in Temara and Skoura (Table 1). Both sites were equipped with meteorological stations enabling high-frequency measurements of various parameters. Temperature, relative humidity, wind speed and direction, total solar irradiation, UVA/UVB irradiation, IR irradiation, and rainfall measurements are recorded every $10 \mathrm{~s}$. Mirrors facing the sun were exposed, at an angle equal to the latitude of exposure site, in racks enabling placing two different mirror sizes: $7 \times 7 \mathrm{~cm}^{2}$ and $20 \times 20 \mathrm{~cm}^{2}$. Different frequencies were used for site visits conducted to characterize aged samples: 7, 15, 30, and 60 days. After each exposure period, samples were cleaned with deionized water during site visits.

\subsubsection{Exposure in Temara}

Mirrors were exposed at $32^{\circ}$ to the horizontal for 24 months in the seaside site. The exposure start date and total exposure time of each sample used in this study is given in Table 3.

Table 3. Exposure start date and exposure time for mirrors tested at the seaside site.

\begin{tabular}{ccc}
\hline Mirror Sample & Exposure Start Date & Exposure Time (Days) \\
\hline A1-12 & 11 October 2012 & 77 \\
A1-13 & 11 October 2012 & 77 \\
A1-14 & 11 October 2012 & 250 \\
A1-15 & 11 October 2012 & 250 \\
A1-18 & 11 October 2012 & 416 \\
A1-19 & 11 October 2012 \\
A1-20 & 11 October 2012 & 416 \\
C2-2 & 27 March 2013 & 615 \\
C2-9 & 25 July 2013 & 541 \\
C2-10 & 25 July 2013 & 423 \\
C2-11 $2-12 ~$ & 25July 2013 & 478 \\
D2-2 & 25 July 2013 & 442 \\
D2-9 & 27 July 2013 & 427 \\
D2-10 & 25 July 2013 & 541 \\
D2-11 & 25 July 2013 & 423 \\
D2-12 & 25 July 2013 & 478 \\
& 25 July 2013 & 442 \\
\hline
\end{tabular}

The seaside site is located in Temara on the Atlantic shore near Rabat city (Northern Morocco, Figure 1). This site has a very aggressive humid and salty weather together with strong winds during the different seasons of the year. It is situated very close to a cliff; samples are then subjected to a very important saline mist [6]. The monthly average climatic parameters of Temara site are given in Table 4.

Table 4. Mean, minimum, and maximum values of weather conditions during exposure period time at the seaside site.

\begin{tabular}{cccccc}
\hline Value & Air Temperature ${ }^{\circ} \mathbf{C}$ & $\begin{array}{c}\text { Total Irradiation } \\
\left(\mathbf{k W h} / \mathbf{m}^{\mathbf{2}}\right)\end{array}$ & $\begin{array}{c}\text { Relative Humidity } \\
\mathbf{( \% )}\end{array}$ & $\begin{array}{c}\text { Daily Rainfall } \\
\mathbf{( m m})\end{array}$ & Wind Speed (m/s) \\
\hline Mean & 17.7 & 5.4 & 81.2 & 1.5 & 2.47 \\
Maximum & 32.1 & 8.8 & 99.7 & 53.4 & 2.82 \\
Minimum & 5.7 & 0.6 & 33.5 & 0 & 1.85 \\
\hline
\end{tabular}




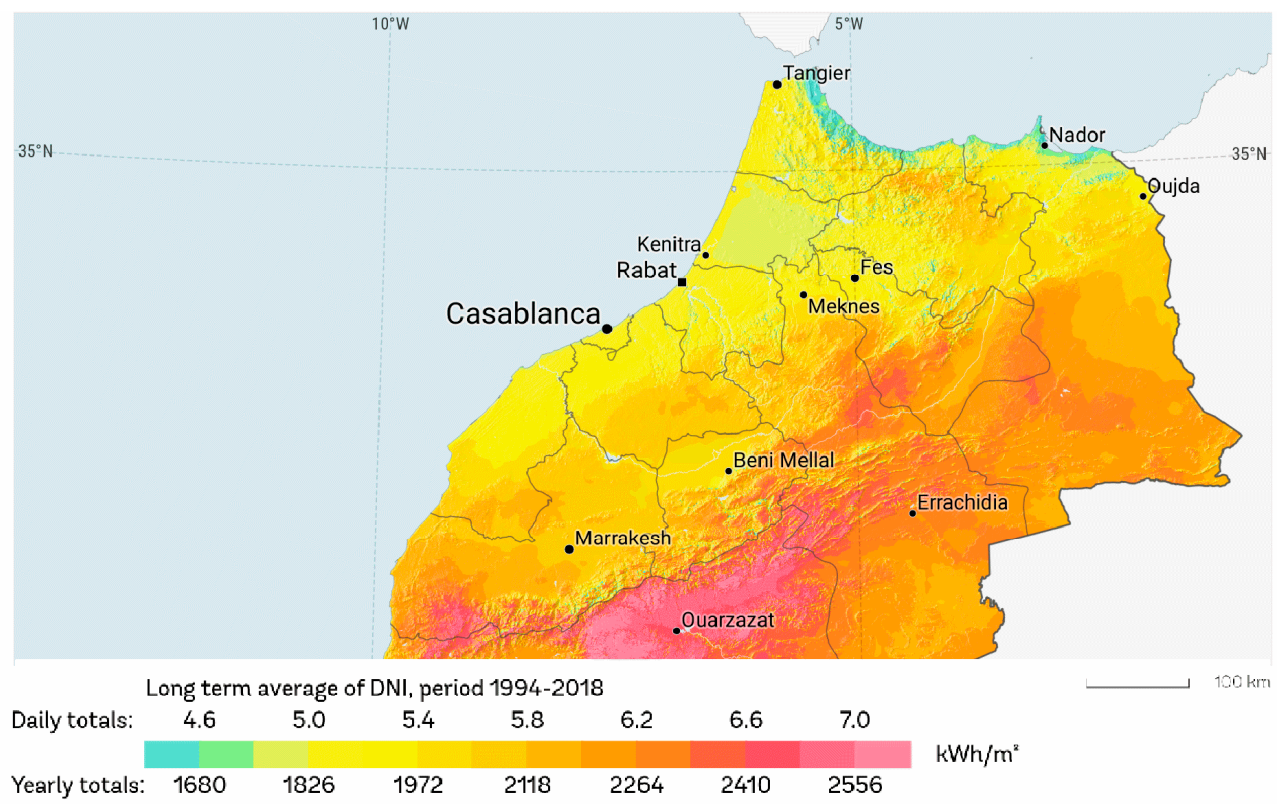

Figure 1. Locations on a map of Morocco of both outdoor sites used for exposure tests. Maroc (SolarGis.info).

\subsubsection{Exposure in Skoura}

Mirrors were exposed at $45^{\circ}$ to the horizontal for 22 months. Meteorological parameters for this exposure site are presented in Table 5.

Table 5. Mean, minimum, and maximum values of weather conditions during exposure period time at the desert site.

\begin{tabular}{cccccc}
\hline Value & Air Temperature ${ }^{\circ} \mathbf{C}$ & $\begin{array}{c}\text { Total Irradiation } \\
\left(\mathbf{k W h} / \mathbf{m}^{\mathbf{2}}\right)\end{array}$ & $\begin{array}{c}\text { Relative Humidity } \\
\mathbf{( \% )}\end{array}$ & $\begin{array}{c}\text { Daily Rainfall } \\
\mathbf{( m m})\end{array}$ & Wind Speed (m/s) \\
\hline Mean & 17.8 & 5.9 & 30.1 & 0.36 & 1.67 \\
Maximum & 32.7 & 7.9 & 99.3 & 64.3 & 0 \\
Minimum & 5.7 & 0.6 & 1.8 & 0 & 0.94 \\
\hline
\end{tabular}

Two exposure periods were used: 30 and 60 days. The exposure start dates and total exposure time of all tested samples are summarized in Table 6 .

\subsection{Analysis of Mirrors Degradation}

Other analytical techniques were performed on tested mirrors in order to characterize and follow the mirrors degradation during exposure time. Every site visit, mirrors are controlled on exposure sites by measuring their specular reflectance before and after cleaning. This allows measuring the reflectivity loss due to the mirrors aging. Reflectance is measured for all samples using a portable spectrophotometer model 15R (Devices and Services, Dallas, TX, USA) which allows measuring the specular reflectance at $660 \mathrm{~nm}$ with $15^{\circ}$ incidence angle and $12.5 \mathrm{mrad}$ acceptance angle in the center of the sample at three to five different points. Mirrors are cleaned using deionized water and optical wet paper to remove adhered soils. Finally, cleaned samples are wiped with a dry optical paper. Every three months the surface degradations of aged mirrors are characterized in laboratory by a Nikon LV150 optical microscope (Nikon Instruments Europe BV, Amsterdam, The Netherlands). The results of these analyses are discussed in a previous publication $[6,23]$. 
Table 6. Exposure start date and exposure time for mirrors tested at the desert site.

\begin{tabular}{ccc}
\hline Mirror Sample & Exposure Start Date & Exposure Time (Days) \\
\hline A1-2 & 30 April 2013 & 664 \\
A1-3 & 30 April 2013 & 664 \\
A1-5 & 30 April 2013 & 664 \\
A1-8 & 27 August 2013 \\
A1-9 & 27 August 2013 & 545 \\
C2-5 & 30 April 2013 & 545 \\
C2-6 & 30 April 2013 & 664 \\
C2-7 & 30 April 2013 & 419 \\
C2-8 & 30 April 2013 & 664 \\
C2-13 & 27 August 2013 & 664 \\
C2-14 & 27 August 2013 & 545 \\
D2-5 & 30 April 2013 & 545 \\
D2-6 & 30 April 2013 & 664 \\
D2-7 & 30 April 2013 & 421 \\
D2-13 & 30 April 2013 & 664 \\
& 27 August 2013 & 664 \\
\hline
\end{tabular}

\subsection{Color Measurements}

Color measurements were carried out using portable colorimeter from BYK (spectroguide $45^{\circ} / 0^{\circ}$ gloss) which allow measuring color in two different spaces (CIE $L^{*} a^{*} b^{*}$, CIE $X Y Z$ ). The (CIE $\left.L^{*} a^{*} b^{*}\right)$ space is the most commonly used. This system uses three spatial coordinates to define color. The $L$ parameter represents the brightness $(L=0$ corresponds to black, $L=100$ corresponds to white), while $\mathrm{a}$ and $\mathrm{b}$ are the color-opponent dimensions: $\mathrm{a}$ is the red/green balance (negative values corresponds to green and positive values corresponds to red), and $\mathrm{b}$ is the yellow/blue balance (negative values corresponds to blue and positive values corresponds to yellow) [26].

The overall color difference $(\Delta E)$ was calculated for each sample using Equation (1) [27]:

$$
\Delta E=\sqrt{\Delta L^{2}+\Delta a^{2}+\Delta b^{2}}
$$

where $\Delta L, \Delta a$ and $\Delta b$ are differences in the respective values before and after aging. The variation of gloss parameter $(\Delta G)$ was calculated for each sample using Equation (2):

$$
\Delta G=G(t)-G(0)
$$

where $G(0)$ and $G(t)$ correspond to the average gloss values calculated, respectively, before exposure tests and after each exposure time $(t)$ during aging tests.

CIE XYZ space allows measuring yellowness (Yi) of paint calculated according to the ASTM standard E313 method [28]. The following equation is used:

$$
Y i=\frac{100\left(C_{x} X-C_{z} Z\right)}{Y}
$$

where $X, Y$, and $Z$ are the space coordinates on the CIE $X Y Z$ space, and $C_{x}$ and $C_{z}$ are constants.

Six measurements were performed on each sample at different locations. The average value was calculated and reported in this paper. The measurements were taken directly on the back of the mirrors to measure the color parameters of the upper layer (white layer) [6]. Three measurements were performed on different locations on the back of each sample.

\subsection{ATR-FTIR Spectroscopy Analysis}

FTIR (Fourier transform infrared) spectroscopy analyses were performed employing a spectrometer Spectrum 400 from Perkin Elmer (Buckinghamshire, UK) equipped with an attenuated total reflection accessory (ATR). The resolution was set at $4 \mathrm{~cm}^{-1}, 64$ scans were recorded for each analysis, and the scanning range was from 650 to $4000 \mathrm{~cm}^{-1}$. FTIR- 
ATR analyses of aged paint samples were conducted in order to follow paint structure modification during aging time. For this reason, we have compared infrared spectra of aged paints with the unexposed paint spectrum for each mirror type. This comparison was carried out by monitoring the evolution of peaks ratio during time. For this reason, all spectra have been normalized by the absorption band of the $\mathrm{C}-\mathrm{O}-\mathrm{C}$ vibration at 1010 $\mathrm{cm}^{-1}$. Three specimens were analyzed per mirror type.

\section{Results}

\subsection{FTIR-ATR}

In order to characterize the aging of the chemical structure of tested paints, infrared spectroscopy was performed on samples before and after exposure. Spectra of non-exposed and exposed samples are presented in Figures 2-4.
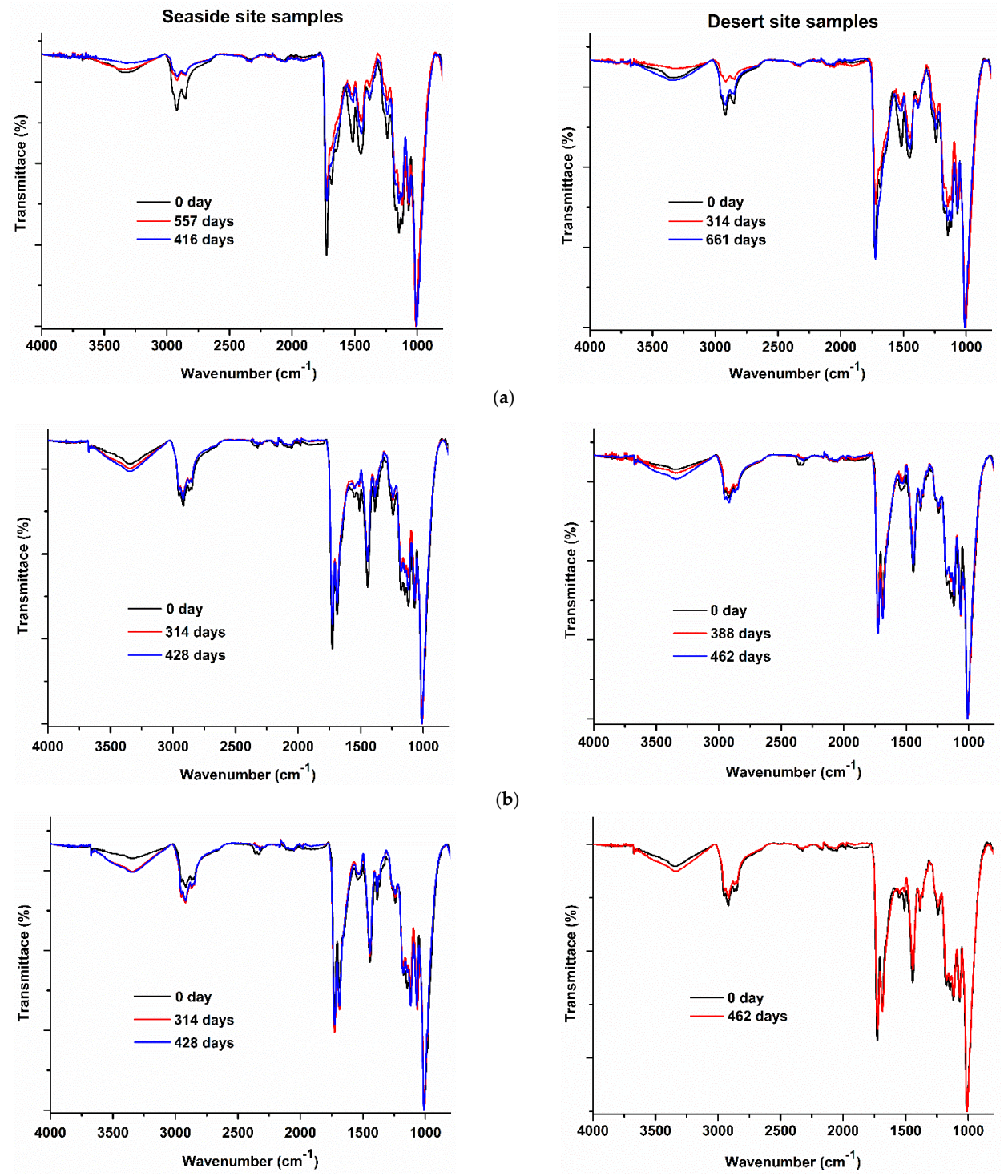

(b)

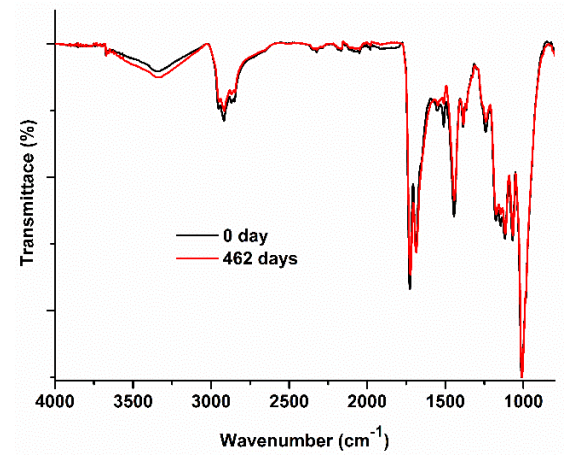

(c)

Figure 2. FTIR-ATR paint spectra of (a) mirror A1, (b) mirror C2, and (c) mirror D2, exposed on both outdoor testing sites (Seaside and desert sites). 


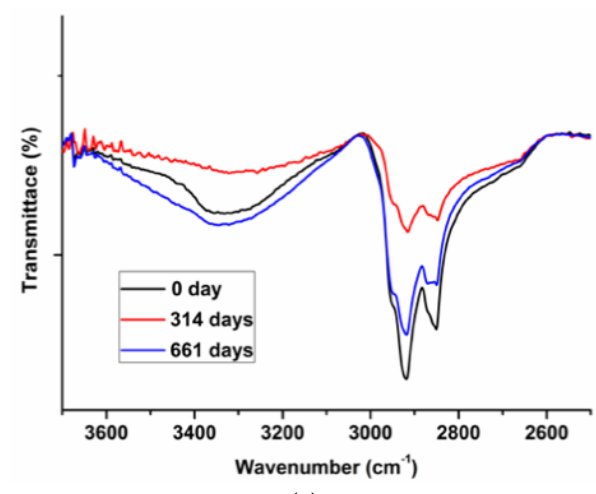

(a)

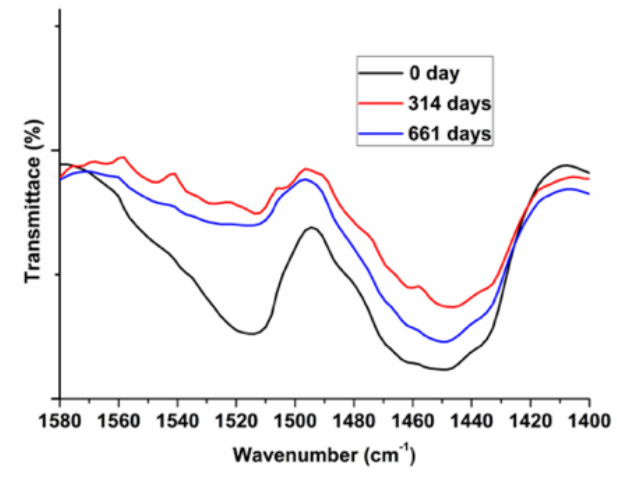

(c)

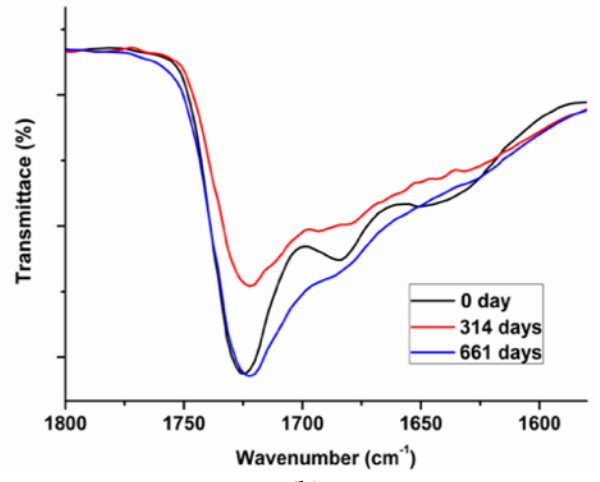

(b)

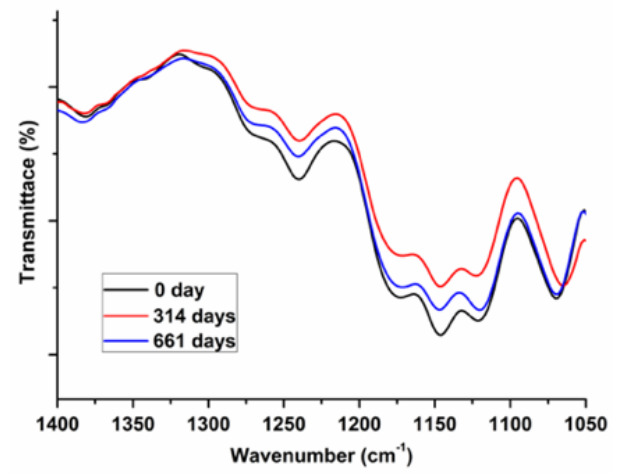

(d)

Figure 3. Windows of FTIR-ATR spectra of mirror A1 paint samples before and after exposure at the seaside site. (a) $3500-2500 \mathrm{~cm}^{-1}$; (b) $1800-1500 \mathrm{~cm}^{-1}$; (c) $1580-1400 \mathrm{~cm}^{-1}$; (d) $1400-1050 \mathrm{~cm}^{-1}$.

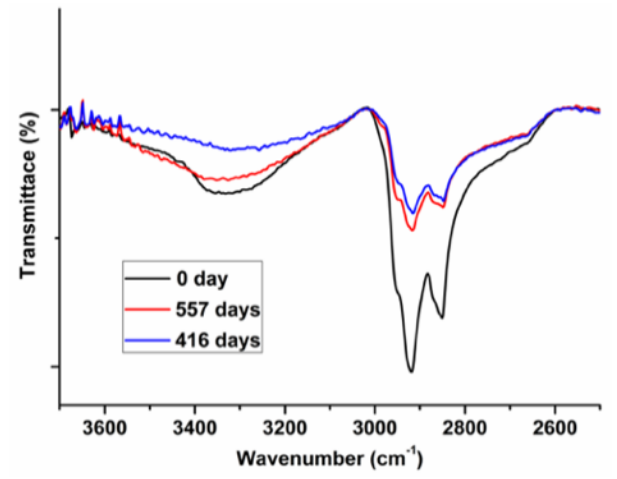

(a)

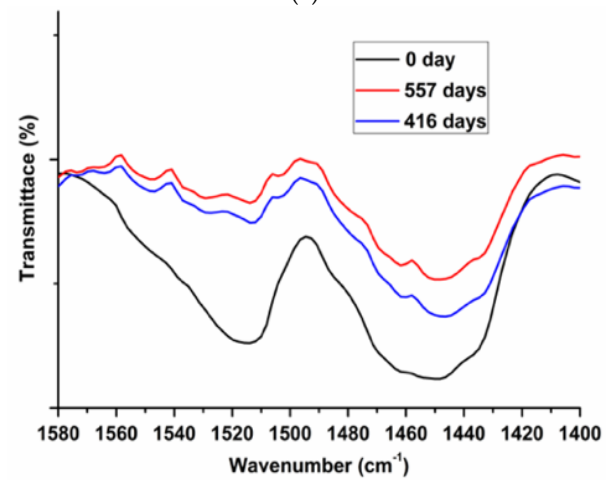

(c)

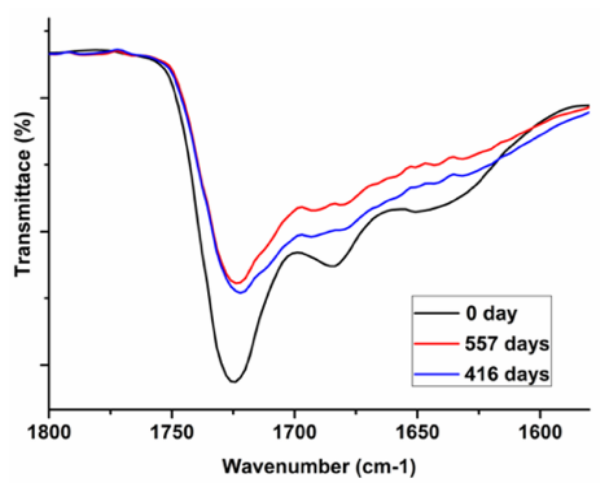

(b)

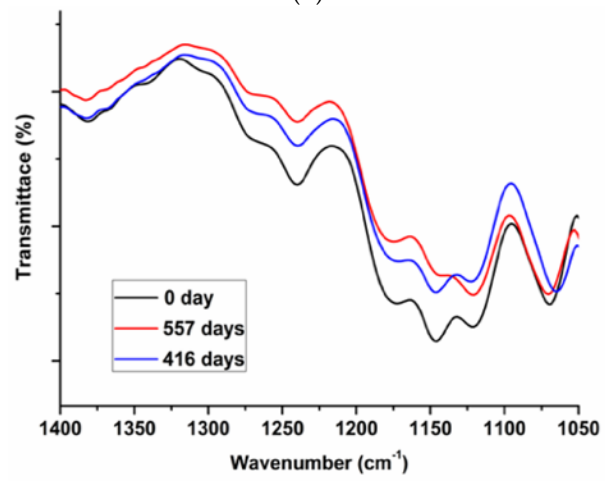

(d)

Figure 4. Windows of FTIR-ATR spectra of mirror A1 paint samples before and after exposure at the desert site. (a) $3500-2500 \mathrm{~cm}^{-1}$; (b) $1800-1500 \mathrm{~cm}^{-1}$; (c) $1580-1400 \mathrm{~cm}^{-1}$; (d) $1400-1050 \mathrm{~cm}^{-1}$. 
Many changes were observed on Mirror type A1 after exposure at both sites. Concerning mirrors C2 and D2, no significant differences were detected between samples analyzed before and after exposure, except the absorption bands at $3650-3100 \mathrm{~cm}^{-1}$ and $2926-2855 \mathrm{~cm}^{-1}$. Table 7 lists the main functional groups and pigments of paint samples.

Table 7. FTIR-ATR infrared absorption of white paint used in tested mirrors.

\begin{tabular}{|c|c|}
\hline Wavenumber $\left(\mathrm{cm}^{-1}\right)$ & Functional Groups and Pigments \\
\hline $3800-3250$ & $\mathrm{O}-\mathrm{H} ; \mathrm{N}-\mathrm{H}$ \\
\hline 2962-2872 & $\mathrm{C}-\mathrm{H}$ Stretching $\left(\mathrm{CH}_{3}\right)$ \\
\hline $2926-2853$ & $\mathrm{C}-\mathrm{H}$ Stretching $\left(\mathrm{CH}_{2}\right)$ \\
\hline 1720 & $\mathrm{C}=\mathrm{O}$ stretching of the esters \\
\hline $1507-1489$ & $\mathrm{C}=\mathrm{C}$ stretching of the polybasic acid \\
\hline 1450 & $\mathrm{C}-\mathrm{H}$ asymmetric stretching $\left(\mathrm{CH}_{3}\right)$ \\
\hline 1420 & $\mathrm{C}=\mathrm{O}$ stretching sym $\left(\mathrm{CO}_{3}-\right.$ from $\left.\mathrm{CaCO}_{3}\right)$ \\
\hline 1381 & $\mathrm{C}-\mathrm{H}$ Symetric $\left(\mathrm{CH}_{3}\right)$ \\
\hline 1240 & C-O Stretching (arylesters) \\
\hline 1174 & $\mathrm{v}(\mathrm{C}-\mathrm{O})$ of ester (cottonseed oil), $\mathrm{TiO}_{2}$ et $\mathrm{BaSO}_{4}$ vibration \\
\hline 1119 & $\mathrm{v}(\mathrm{C}-\mathrm{O})$ of $\mathrm{O}-\mathrm{CH}_{2}$ (phthalate) and $\mathrm{BaSO}_{4}$ vibration \\
\hline $1070-1038$ & in plane deformation of aromatic $\mathrm{CH}$ and $\mathrm{BaSO} 4$ vibration \\
\hline 1016 & $\mathrm{C}-\mathrm{O}-\mathrm{C}, \mathrm{TiO}_{2}, \mathrm{SiO}_{2}$ Stretching \\
\hline
\end{tabular}

By considering the following infrared regions, it is possible to describe the chemical modifications observed on paint structure for tested mirrors [22,29,30]:

- $\quad \mathrm{O}-\mathrm{H}$ and $\mathrm{N}-\mathrm{H}$ stretching $\left(3650-3100 \mathrm{~cm}^{-1}\right)$ : An increase of the relative intensity in this region was observed on infrared spectra of mirror 2 samples after 314 exposure days. Changes in this infrared region may be interpreted as a partial depolymerization of the organic matrix's structure. These latter bonds may be assigned to the symmetric and asymmetric stretching vibrations of $\mathrm{N}-\mathrm{H}$ links in secondary or in primary (amine functions and/or to the characteristic vibrations of the O-H hydroxyl groups [29]. The formation of amino and/or hydroxyl functional groups suggested that the degradation reactions occurred at the level where the resins crosslink. The crosslinking of the paint is achieved with the HMMM resin and forms ether links with the alkyd resin. This could be explained by the degradation mechanism proposed by in which paint degradation occurred in two steps: The first step consists of a hydrolysis reaction of the ether links in order to form terminal hydroxyl groups on the alkyd resin and methylol groups $\left(-\mathrm{CH}_{2}-\mathrm{OH}\right)$ on the melamine resin; during the second step, the methylol groups previously formed may then hydrolyze giving way to primary and secondary amine functions.

- C-H stretching (2926 and $2855 \mathrm{~cm}^{-1}$ ): A decrease of the infrared region at 2926 and $2855 \mathrm{~cm}^{-1}$ can be noticed for mirror A1 exposed at Temara site after 416 days. The methylene groups of the paint binder were prone to diminish possibly due to the oxidation of double bonds which is shown by a gradual decrease in absorption in the asymmetric and symmetric $(\mathrm{C}-\mathrm{H}) \mathrm{CH}_{2}$ stretching at this region.

- $\mathrm{C}=\mathrm{O}$ stretching $\left(1750-1700 \mathrm{~cm}^{-1}\right)$ : A decrease was observed on the carbonyl stretching absorption at $1720 \mathrm{~cm}^{-1}$, for mirror A1 exposed at Temara and Skoura site after 554 and 314 days, respectively. This modification could due to thermal oxidation of the binder during aging $[22,30]$.

- $\mathrm{C}=\mathrm{C}$ of aromatic ring $\left(1650-1450 \mathrm{~cm}^{-1}\right)$ : The peak centered at $1507 \mathrm{~cm}^{-1}$ attributed to the aromatic stretching of the $\mathrm{C}=\mathrm{C}$ bond of the polybasic acid part of the alkyd binder, was no longer present in infrared spectra of mirror A1 exposed at Temara and Skoura site after 557 and 314 days, respectively. This is probably due to the scission of the polymeric chain of the paint binder caused by UV aging of paint samples at both sites.

- $\quad\left(1254-1070 \mathrm{~cm}^{-1}\right)$ : A slight decrease in the intensity of the peaks at this infrared region was noticed for Mirrors A1 exposed at Temara site. This infrared region is attributed to several bond vibrations of both phases (organic binder and mineral pigments) 
composing the white paints of monolithic mirrors. The absorption bands of the binder and pigments (in particular $\mathrm{TiO}_{2}, \mathrm{CaCO}_{3}$, and $\mathrm{BaSO}_{4}$ ) overlap in this region.

For example, the absorption peak of $\mathrm{CaCO}_{3}$ at $1420 \mathrm{~cm}^{-1}$ is hidden by the asymmetric elongation band of the $\mathrm{C}-\mathrm{H}$ bond. Similarly, the $\mathrm{C}-\mathrm{O}$ bonds of the polymeric binder hide the absorption bands of $\mathrm{BaSO}_{4}$ pigments at 1174 and $119 \mathrm{~cm}^{-1}$. In addition, these pigments are also hidden by two peaks corresponding to the aromatic vibrations $\mathrm{C}-\mathrm{H}$ at 1070 and $1038 \mathrm{~cm}^{-1}$. Thus, the changes at this region could be due to pigments degradation at this humid site.

\subsection{Colorimetric Measurements}

The color measurement results of all tested paints exposed at both sites are summarized in Figures 5-9, which include the gloss change $(\Delta G)$, total color change $(\Delta E)$, redness/greenness $\left(\Delta a^{*}\right)$, yellowness/blueness $\left(\Delta b^{*}\right)$, and the yellowing $(\Delta Y i)$.
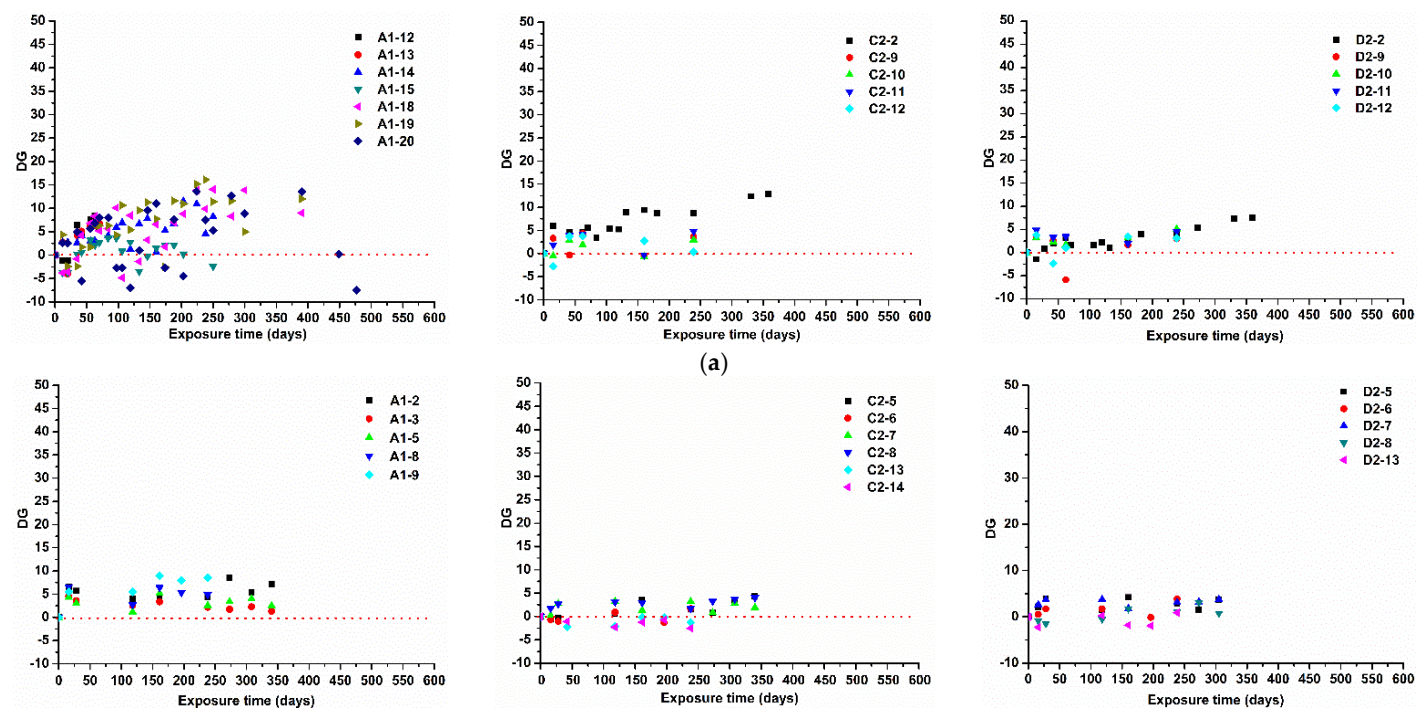

(b)

Figure 5. Evolution of gloss variation $(\Delta G)$ of monolithic mirrors A1, C2, and D2 paint coatings during exposure time at (a) the seaside site and $(\mathbf{b})$ desert site.
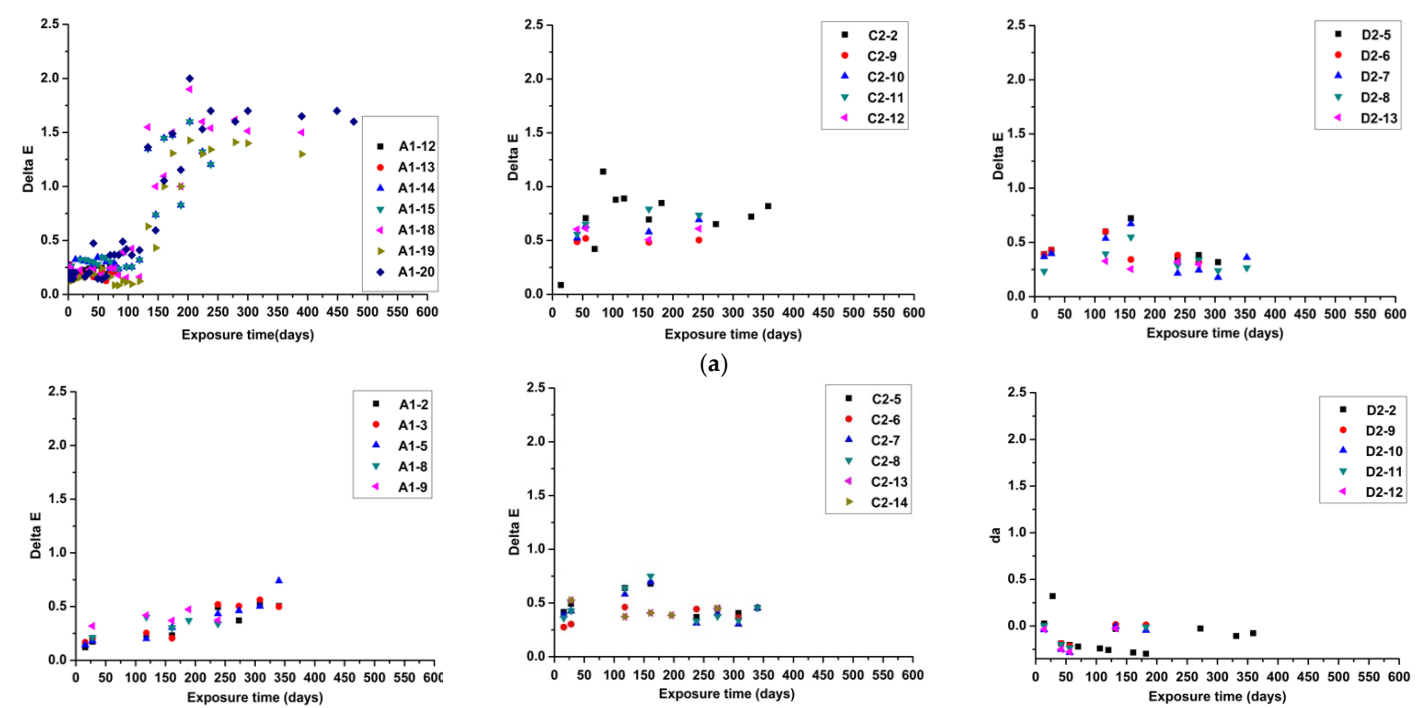

(b)

Figure 6. Evolution of total color change $(\Delta E)$ of monolithic mirrors A1, C2, and D2 paint coatings during exposure time at (a) the seaside site and (b) desert site. 


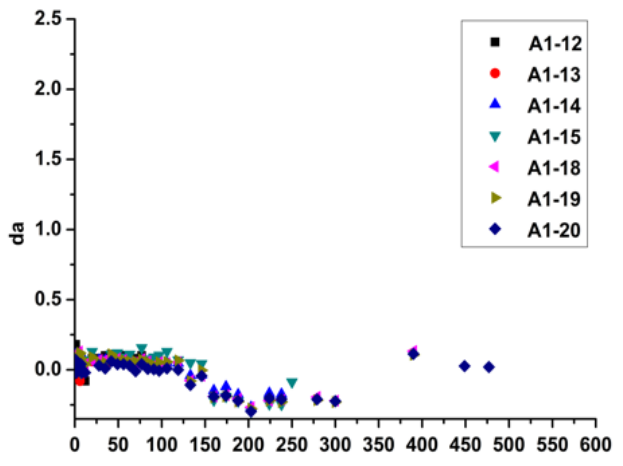

Exposure time (days)

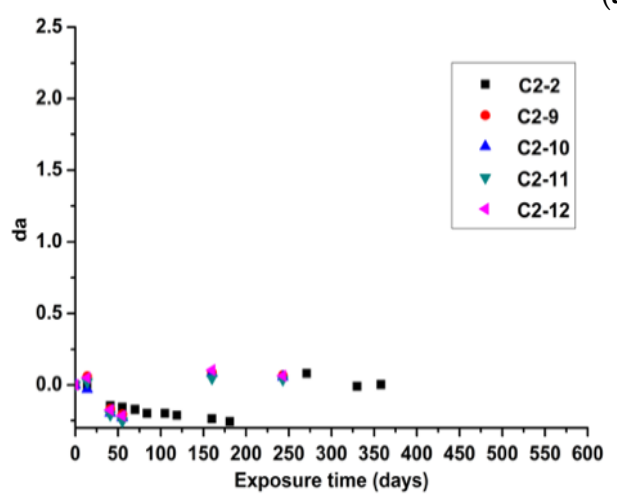

(b)
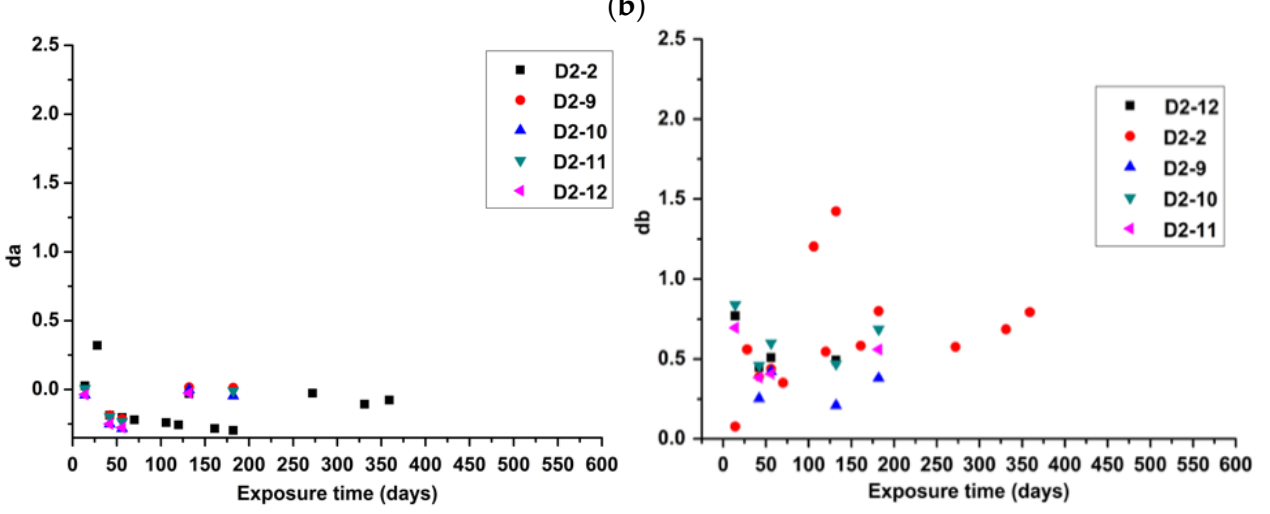

(c)

(a)
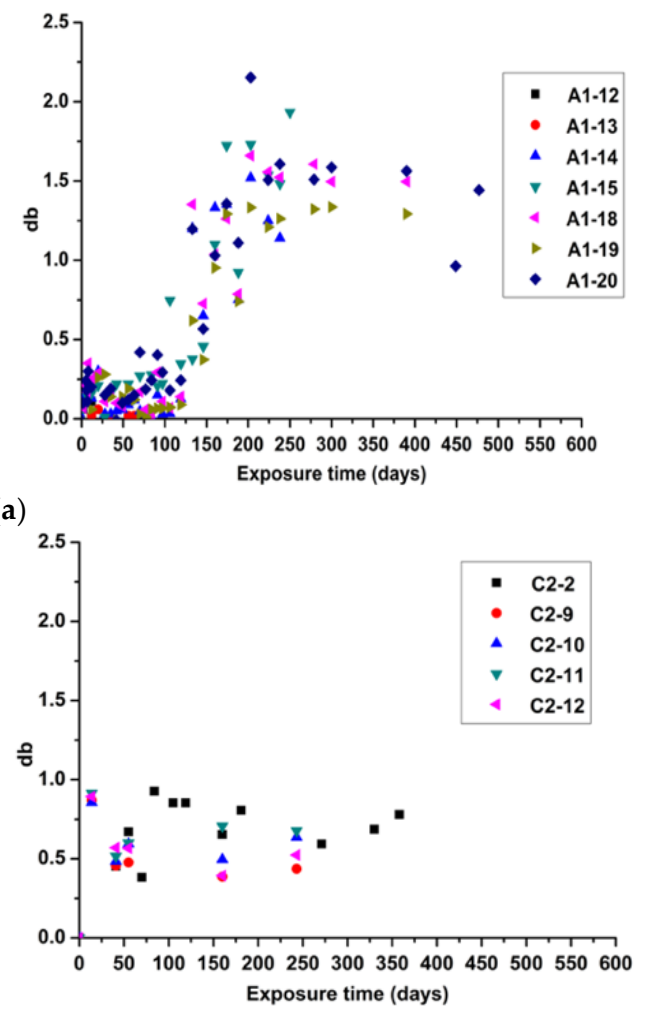

Figure 7. Evolution of color parameters $(\Delta a$ and $\Delta b)$ of monolithic mirrors (a) A1, (b) C2, and (c) D2 paint coatings during exposure time at the seaside site.
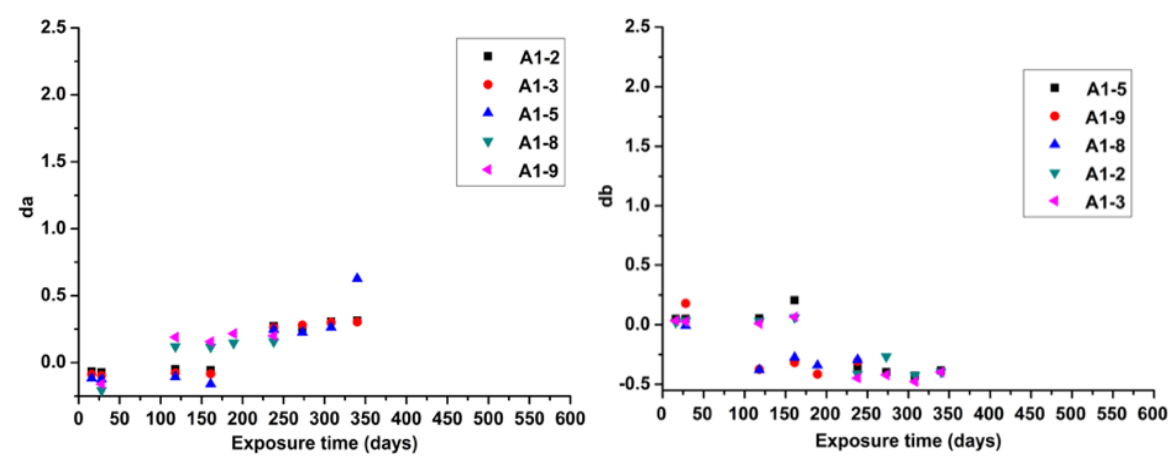

(a) 

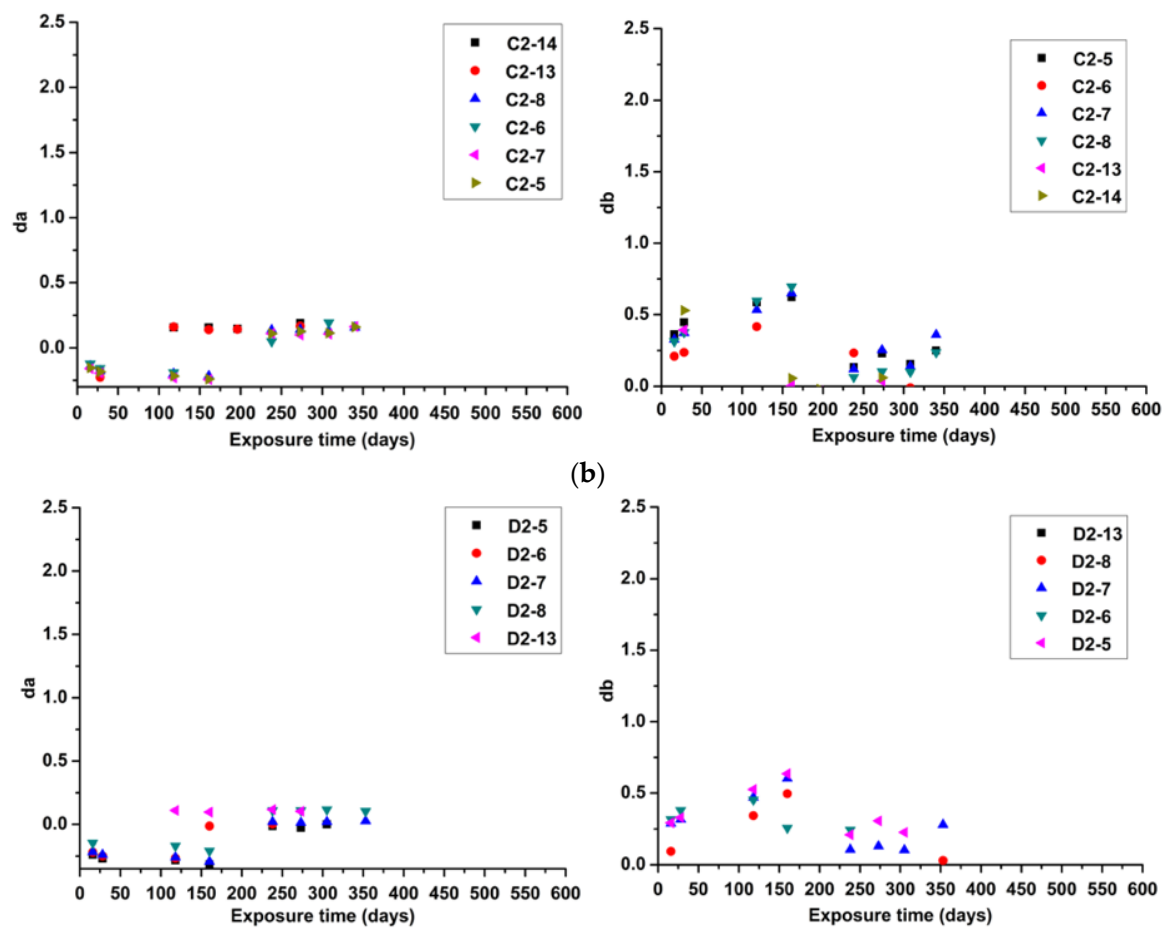

(c)

Figure 8. Evolution of color parameters $(\Delta a$ and $\Delta b$ ) of monolithic mirrors (a) A1, (b) C2, and (c) D2 paint coatings during exposure time at the desert site.

The gloss change $(\Delta G)$ during aging at both exposure sites is presented in Figure 5. For the desert site, the tested samples in general preserved their original gloss after 300 days. An intriguing fact is that a moderately increasing trend was observed dependent on the mirror's type. For the seaside site, an important increasing trend of gloss was observed for mirrors C2 and D2, especially after 350 days. In the case of mirror A1, the gloss change was totally different. The initial increase during the first 100 days was followed by a decrease until 170 days, and then the trend increased again for the majority of exposed samples. For the most exposed sample (A1-20), an important decrease in gloss was observed after 450 days. This gloss evolution of mirror A1 may be due to moisture content in samples fluctuating after each exposure period of time at this very humid site.

The obtained curves for total color change $(\Delta E)$ show an increase during time for paint samples exposed at the seaside site compared to a small variation for paint samples exposed at the desert site. The higher the $\Delta E$ is, the higher the overall color modification of paint coatings. For samples exposed at the desert site, the $\Delta E$ values were lower and stable around 0.5. Concerning paint samples exposed at the seaside site, paint of mirror 2 (C2 and D2) have presented more color stability than paints of mirrors type 1 (A1) after more than 350 exposure days, with discoloration values of 1 and 2, respectively.

The analysis of $\Delta a$ and $\Delta b$ variation shows a clear correlation between total color change $(\Delta E)$ and total yellowness/blueness $(\Delta b)$ variation (Figures 7 and 8). According to Figure $7, \Delta a$ has tended to remain stable throughout the entire duration of the exposure test while $\Delta b$ has shown a similar variation during time than $\Delta E$ for the three paints. The $\Delta b$ increase is an indicator of a color shift from white to yellow in the CIE Lab color space. This indicates a yellowing of the top coating paint of monolithic mirrors during aging time at the seaside site. Moreover, Figure 7 shows that $\Delta b$ variation was more important for mirror A1, which explains the significant total color change observed on this mirrors type compared to mirrors $\mathrm{C} 2$ and D2. 

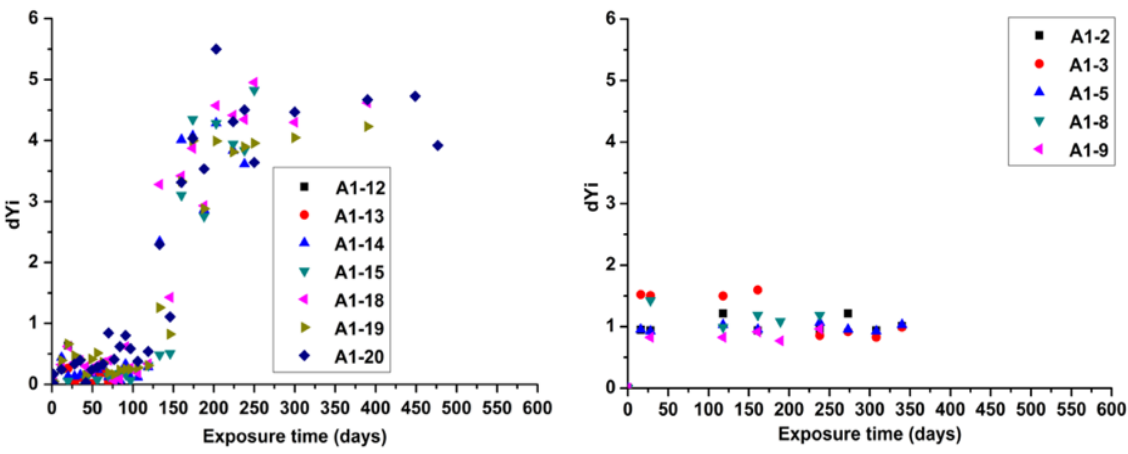

(a)
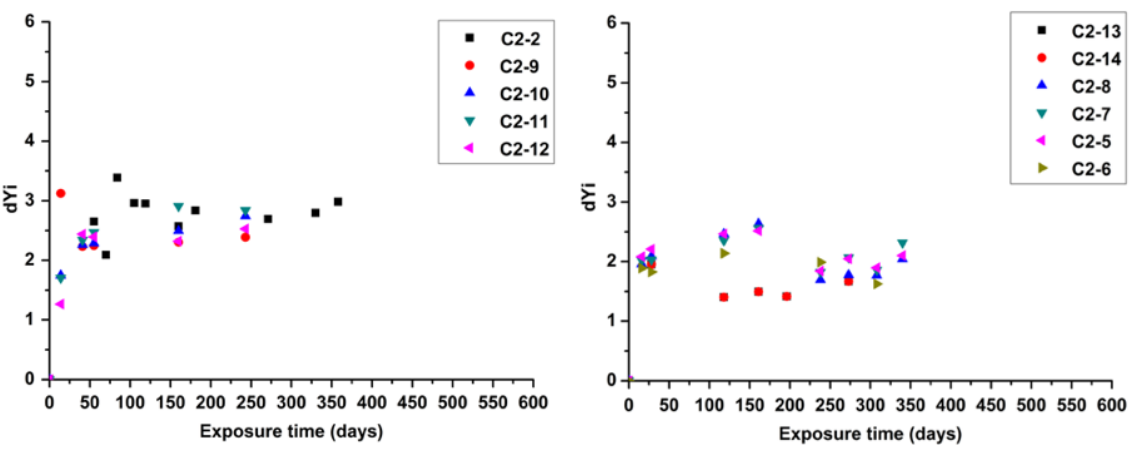

(b)
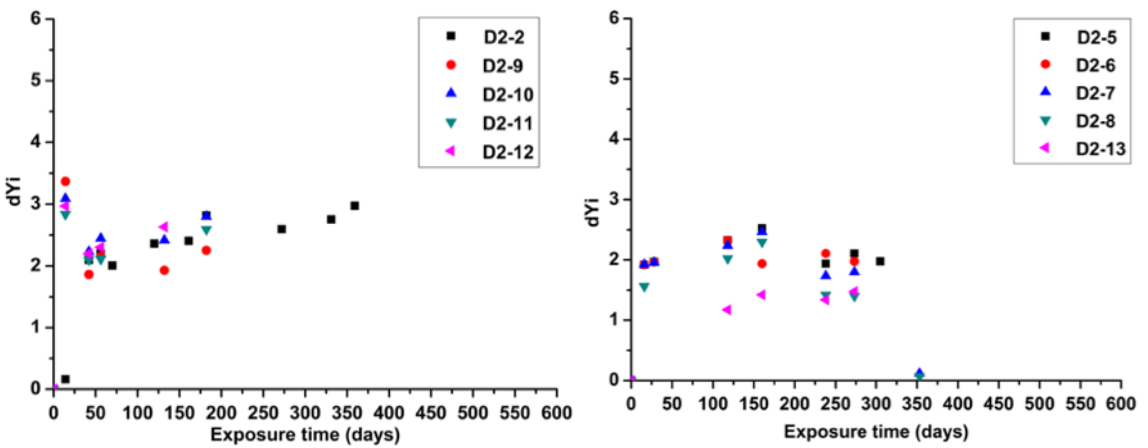

(c)

Figure 9. Evolution of yellowing parameter $(\Delta Y i)$ of monolithic mirrors (a) A1, (b) C2, and (c) D2 paint coatings for samples exposed at the seaside site (left) and the desert site (right).

The yellowing parameter (Yi) measurements results confirm this latter result. As can be seen from Figure 9, this parameter, calculated in CIE XYZ color space, presents a similar variation during time than both parameters $(\Delta E$ and $\Delta b)$ of CIE Lab space. This confirms that color change observed on the monolithic mirrors top paints is due to yellowing of white paint coatings and it is more significant for mirrors A1. This result agrees with the FTIR-ATR results. Indeed, yellowing is a paint discoloration which could result from different chemical degradation mechanisms of paints: photodegradation, binder degradation, degradation of additives, and the presence of impurities [21,31-35]. The chemical degradation of paints during exposure leads to changes in the physical appearance and performance of the top coating (color change, gloss loss, cracking, peeling, or chalking) and, thus, impacts the protective properties of other paint layers as well as the metallic layers. Contaminants (UV, $\mathrm{H}_{2} \mathrm{O}, \mathrm{O}_{2}$, salts, etc.) presented at exposure sites could then penetrate through aged paint coatings and cause metallic layer corrosion [6].

Paint coatings, as well as other layers composed monolithic glass mirrors, are subject to physico-chemical degradation when exposed to natural environments. The severity of degradation is related to the aggressivity of exposure environments. The degradation of paint films alters their protective role and causes corrosion of reflective layer and, therefore, decreases the lifetime of solar mirrors. Many parameters influence the durability of paints, 
such as temperature, humidity, and solar irradiation. Photodegradation is the main factor causing surface degradation of paint. For this reason, modifications due to exposures were compared using the UV dose received by paint samples during aging time. Figure 10 shows the yellowing $(Y i)$ values of tested paints in terms of two kinds of abscissa: cumulative total $\mathrm{UV}$ radiation $\left(\mathrm{kWh} \cdot \mathrm{m}^{-2}\right.$ ) and the exposure time in days. Total UV radiation corresponds here to the summation of the different regions of the electromagnetic spectrum, such as the $\mathrm{UV}$, visible, and infrared radiation.
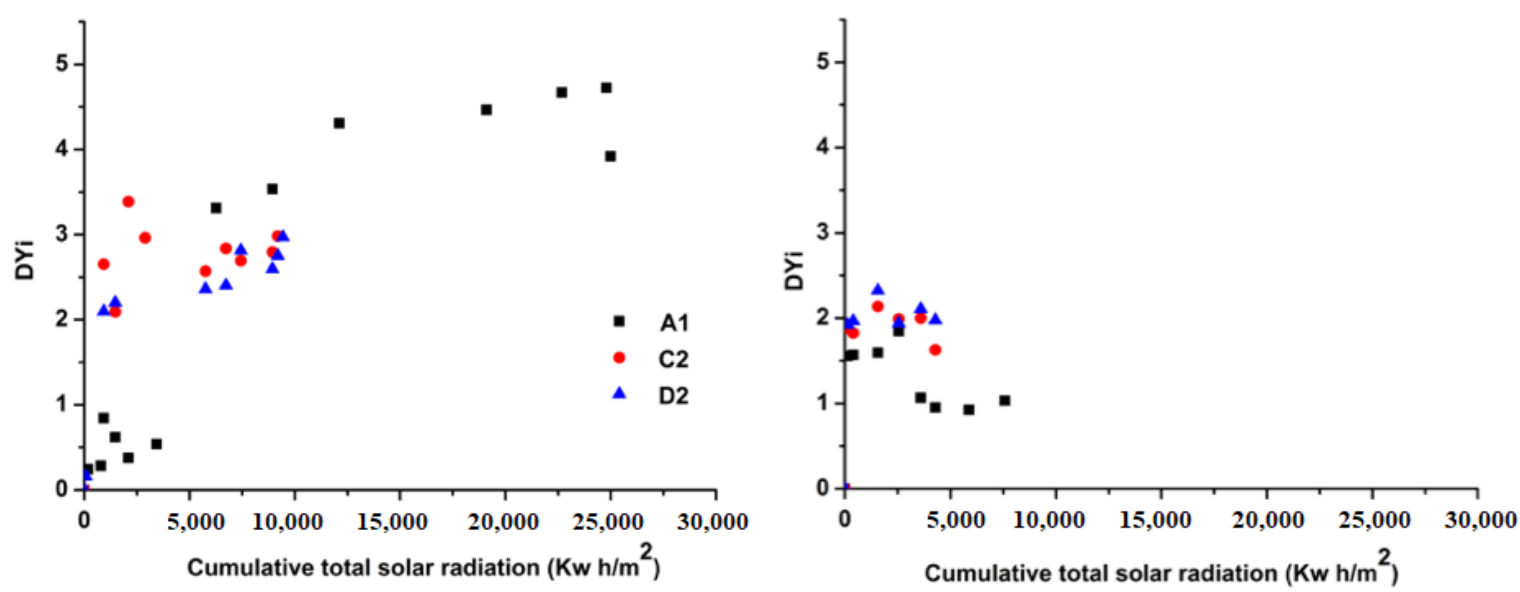

(a)
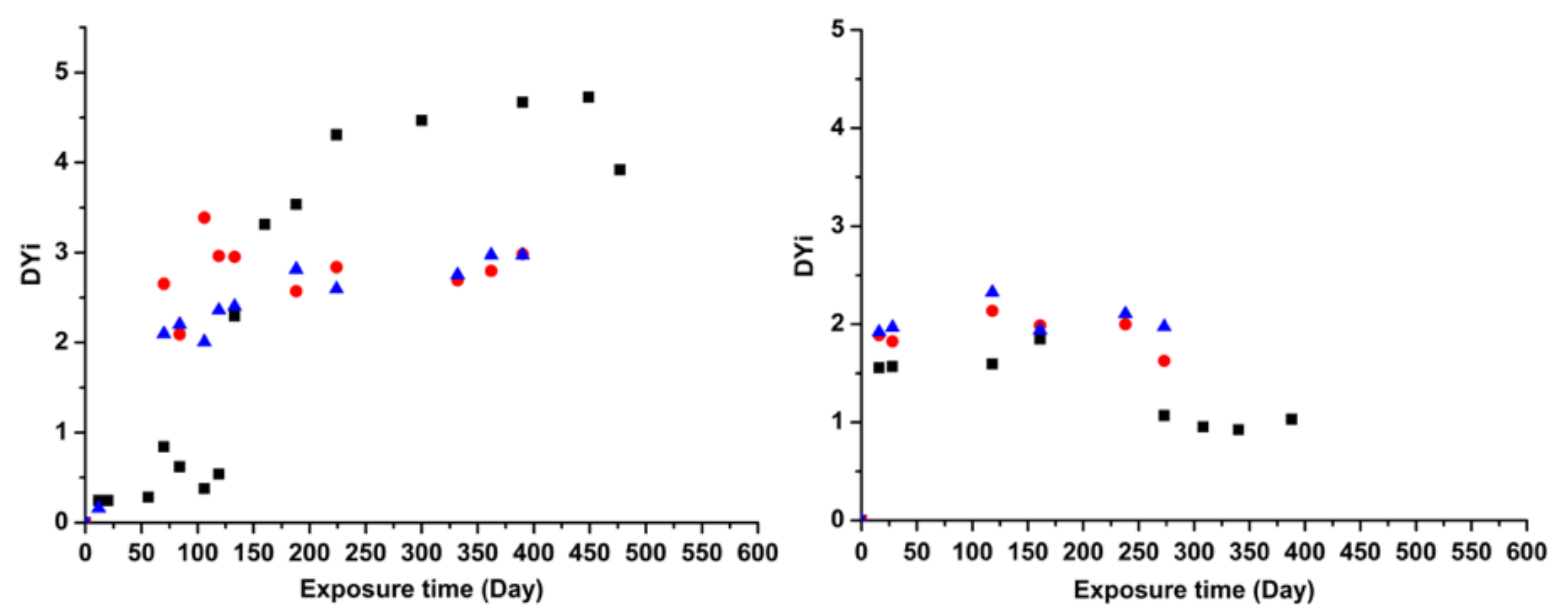

(b)

Figure 10. Evolution of yellowing parameter $(\Delta Y \mathrm{i})$ in function of (a) cumulative solar radiation and (b) exposure time of monolithic mirrors (A1, C2 and D2) paint coatings exposed at the seaside site (left) and the desert site (right).

When analyzing the different curves, it appears that each exposure site has a different impact on the paint and, each paint responds differently. From this figure, it is clearly seen that marine site has causing the most pronounced degradation in terms of yellowness for all tested samples. Moreover, this figure shows that Paint A1 was the most sensitive paint in the marine site and the more resistant paint in the desert one. Since both sites are characterized by very different climates and tested paint have not been exposed in the same period, this finding suggests that degradation cannot be compared simply in terms of the UV or quantity of energy samples receive or the length of time they are exposed to the weather; there are other factors than photo degradation that modify color of paints such as marine salts, erosion and high humidity, etc. 


\section{Overview and Recommendations}

The outdoor tests parameters and the main results obtained from characterizing the aged paints in both exposure sites are summarized in Table 8 . The use of these data will give solar mirrors manufacturers relevant information about the real behavior of paint in desert and marine environmental climates. This will help them to develop best practices for durability testing of solar components and also to choose the most reliable technology of protective paint coatings depending to service conditions of glass mirrors. According to the experimental results of this study, the successful performance of all paints at the desert site, which is characterized by higher irradiation and temperature, indicates that tested paints have high resistance to photo degradation.

Table 8. Summary of the main parameters and results of durability outdoor tests conducted on paints A1, C2, and D2.

\begin{tabular}{|c|c|c|c|c|c|c|c|c|c|}
\hline Site & Paint & Lat. Long & $\begin{array}{c}\text { Total } \\
\text { Solar } \\
\text { Radiation } \\
\left(\mathbf{k W h} / \mathbf{m}^{2}\right)\end{array}$ & $\begin{array}{c}\text { Av. Tem- } \\
\text { perature } \\
\text { (min/max) } \\
{ }^{\circ} \mathrm{C}\end{array}$ & $\begin{array}{c}\text { Av. } \\
\text { Relative } \\
\text { Humidity } \\
(\%)\end{array}$ & $\begin{array}{l}\text { Rain } \\
(\mathrm{mm})\end{array}$ & $\begin{array}{c}\text { Exposure } \\
\text { Time } \\
\text { (Day) }\end{array}$ & $\begin{array}{l}\text { Aging of } \\
\text { Binder } \\
\text { Chemical } \\
\text { Structure }\end{array}$ & $\begin{array}{c}\text { Max } \\
\text { Color } \\
\text { Variation } \\
(\Delta E / \Delta Y i)\end{array}$ \\
\hline \multirow[t]{3}{*}{ Temara } & $\mathrm{A} 1$ & \multirow[t]{3}{*}{$\begin{array}{c}33.90^{\circ} \mathrm{N} \\
6.96^{\circ} \mathrm{W}\end{array}$} & 25,758 & $5.9 / 29.8$ & 81.2 & 764 & 615 & $\begin{array}{c}\text { Many } \\
\text { changes in } \\
\text { FTIR-ATR } \\
\text { spectra }\end{array}$ & $1.6 / 4.7$ \\
\hline & $\mathrm{C} 2$ & & 9950 & $5.9 / 29.8$ & 81.2 & 373 & 495 & Only O-H & $0.8 / 1.7$ \\
\hline & D2 & & 9950 & $5.9 / 29.8$ & 81.2 & 373 & 495 & stretching & $1.0 / 0.7$ \\
\hline \multirow[t]{3}{*}{ Skoura } & A1 & \multirow[t]{3}{*}{$\begin{array}{c}30.94^{\circ} \mathrm{N} \\
6.93^{\circ} \mathrm{W}\end{array}$} & 7570 & $-1.7 / 40.1$ & 26.5 & 301 & 664 & $\begin{array}{c}\text { Many } \\
\text { changes in } \\
\text { FTIR-ATR } \\
\text { spectra }\end{array}$ & $-2.4 / 1.1$ \\
\hline & $\mathrm{C} 2$ & & 4277 & $5 / 40.1$ & 21.3 & 301 & 340 & $\begin{array}{l}\text { Only O-H } \\
\text { stretching }\end{array}$ & $0.3 / 1.6$ \\
\hline & D2 & & 4277 & $5 / 40.1$ & 21.3 & 301 & 340 & - & $-0.7 / 2.0$ \\
\hline
\end{tabular}

For this reason, desert and dry environments could be used to test the resistance of paint against UV radiation. In other hand, the higher rate of degradation in the marine site, characterized by high humidity and salinity, suggests that such extreme environments should be used in order to accelerate the degradation of new developed paints during natural exposure. This will help manufactures to have faster results about paint behavior under natural exposure. As consequence, they will have the possibility to make necessary modifications to their new products after shorter testing time than when using real service conditions or other exposure environments. Additionally, such environments will allow testing the synergic effect of photo degradation and degradation resulting from humidity, salinity, moisture, and rain on paint durability.

Finally, the effect of each climatic and environmental parameter on paint degradation cannot be sufficient analyzed under outdoor exposure. Accelerated exposure tests are important to provide complementary results and also to have an indication of the long-term durability of paints in their end use environment.

\section{Conclusions}

This work investigates the influence of natural aging on chemical structure and color change of top coatings applied on the back of three types of commercial glass mirrors exposed in two different climate conditions in Morocco (Temara and Skoura). The results of colorimetric measurements showed that the coating system used in tested glass mirrors was high resistant to the environmental conditions of the desert site. At this site, there were no obvious changes of paint color and gloss. Under the marine site, certain changes were present for paint samples of mirrors A1: The coatings turned somewhat yellow under the aggressive environmental and meteorological conditions (UV radiation, humidity, 
salinity) and they also showed very moderate gloss degradation after 450 days. Paint samples of mirrors C2 and D2 showed better color stability compared to mirror A1. The characterization of aged samples has indicated chemical modifications during aging of the organic binder especially for samples exposed at the marine site. The comparison made on different samples at both exposure sites have shown that paint yellowing cannot be only correlated to the accumulated UV quantity received by exposed samples nor the test period but to other parameters such as humidity, salinity, and rainfall. Finally, the signs of degradation observed on paint samples at the marine site indicate that such environments could be used to test the durability of glass mirrors paints in a shorter time.

Author Contributions: Conceptualization, M.G. and S.N.; methodology, M.G. and S.N.; validation, S.N., Z.E., O.R. and H.B.; formal analysis, M.G.; investigation, M.G.; data curation, M.G.; writingoriginal draft preparation, M.G. All authors have read and agreed to the published version of the manuscript.

Funding: This project was co-funded by the Moroccan Foundation for Advanced Science Innovation and Research (MAScIR) and the French Alternative Energies and Atomic Energy Commission (CEALITEN).

Institutional Review Board Statement: Not applicable.

Informed Consent Statement: Not applicable.

Data Availability Statement: The data presented in this study are available in [Guerguer, M.; Karim, M.; Naamane, S.; Edfouf, Z.; Raccurt, O. Degradation of solar glass mirrors paints at marine outdoor site. AIP Conf. Proc. 2018, 2033, 230004].

Acknowledgments: The authors would like to thank the MAScIR's technical platform team for their support, Soumia MAZZI, Ismail BENNANI, Mohamed EL KHADRI and Chakib TILSAGHANI.

Conflicts of Interest: The authors declare no conflict of interest.

\section{References}

1. Choukri, K.; Naddami, A.; Hayani, S. Renewable energy in emergent countries: Lessons from energy transition in Morocco. Energy Sustain. Soc. 2017, 7, 1-11. [CrossRef]

2. MEMEE. Speech of the Minister of Energy and Mines during COP21; MEMEE: Paris, France, 2015.

3. Bennouna, A.; El Hebil, C. Energy needs for Morocco 2030, as obtained from GDP-energy and GDP-energy intensity correlations. Energy Policy 2016, 88, 45-55. [CrossRef]

4. Edfouf, Z.; Guerguer, M.; Naamane, S.; Karim, M.; Zari, N.; Grirate, H.; Raccur, O.; Delord, C.; Couturier, R. Research on component materials used for Moroccan CSP power plants: Mirrors ageing and thermal storage. In Proceedings of the International Renewable and Sustainable Energy Conference (IRSEC), Ouarzazate, Morocco, 17-19 October 2014.

5. Delord, C.; Bouquet, C.; Couturier, R.; Raccurt, O. Characterizations of the durability of glass mirrors for CSP, Development of a methodology. In Proceedings of the International Renewable and Sustainable Energy Conference (IRSEC), Ouarzazate, Morocco, 17-19 October 2014.

6. Edfouf, Z.; Guerguer, M.; Raccurt, O. Glass and polymeric mirrors aging under different Moroccan weathers, an application for CSP power plants. Energy Procedia 2015, 69, 1508-1518. [CrossRef]

7. Karim, M.; Condé, M.N.; Edfouf, Z.; Naamane, S.; Belcadi, S.; Raccurt, O.; Delord, C.; Tochon, P. Physico-chemical and mechanical degradations study of Fresnel reflectors of CSP power Plants. In Proceedings of the SolarPACES Conference, Marrakech, Morocco, 11-14 September 2012.

8. Karim, M.; Naamane, S.; Hassani, I.E.A.E.; Delord, C.; Belcadi, S.; Tochon, P.; Bennouna, A. Towards the prediction of CSP mirrors wear: Methodology of analysis of influencing parameters on the mirrors surface degradation: Application in two different sites in Morocco. Sol. Energy 2014, 108, 41-50. [CrossRef]

9. Karim, M.; Naamane, S.; Delord, C.; Bennouna, A. Surface wear damage of glass solar mirrors in Moroccan desert environment. In Proceedings of the 2014 International Renewable and Sustainable Energy Conference (IRSEC), Ouarzazate, Morocco, 17-19 October 2014.

10. Guerguer, M.; Karim, M.; Naamane, S.; Edfouf, Z.; Raccurt, O.; Delord, C. Soiling deposition on solar mirrors exposed in Morocco. In AIP Conference Proceedings; AIP Publishing LLC: Melville, NY, USA, 2017; Volume 1850, p. 130005.

11. Kennedy, C.E. Optical durability of candidate solar reflectors. J. Sol. Energy Eng. 2005, 27, 262. [CrossRef]

12. Fernández-García, A.; Cantos-Soto, M.E.; Röger, M.; Wieckert, C.; Hutter, C.; Martinez-Arcos, L. Durability of solar reflector materials for secondary concentrators used in CSP systems. Sol. Energy Mater. Sol. Cells 2014, 130, 51. [CrossRef] 
13. García-Segura, A.; Fernández-García, A.; Ariza, M.J.; Sutter, F.; Valenzuela, L. Durability studies of solar reflector: A review. Renew. Sustain. Energy Rev. 2016, 62, 453-467. [CrossRef]

14. Schulz, U. Accelerated Testing: Nature and Artificial Weathering in the Coatings Industry; Vincentz Network GmbH \& Co KG: Hannover, Germany, 2008; ISBN 978-3-86630-908-1.

15. Sutter, F.; Fernandez-Garcia, A.; Heller, P.; Anderson, K.; Wilson, G.; Schmücker, M.; Marvig, P. Durability Testing of Silvered-Glass Mirrors. Energy Procedia 2015, 69, 1568-1577. [CrossRef]

16. Sutter, F.; Ziegler, S.; Schmücker, M.; Heller, P.; Pitz-Paal, R. Modeling of optical durability of enhanced aluminum solar reflectors. Sol. Energy Mater. Sol. Cells 2012, 107, 37-45. [CrossRef]

17. Sutter, F.; Fernandez-Garcia, A.; Wette, J.; Heller, P. Comparison and Evaluation of Accelerated Aging Tests for Reflectors. Energy Procedia 2014, 49, 1718-1727. [CrossRef]

18. Kennedy, C.E. Advanced Reflector and Absorber Materials. Thermal Systems Groups: CSP Capabilities. 2010. Available online: www.nrel.gov/csp/pdfs/48662.pdf (accessed on 4 April 2014).

19. Weldon, D. Failure Analysis of Paints and Coatings; Wiley: Hoboken, NJ, USA, 2009.

20. National Renewable Energy Laboratory (NREL). Corrosion and durability Research. 2017. Available online: https://www.nrel. gov / csp/corrosion-durability.html (accessed on 4 April 2018).

21. Jones, F.N.; Nichols, M.E.; Pappas, S.P. Organic Coatings. Science and Technology, 4th ed.; John Wiley \& Sons: Hoboken, NJ, USA, 2017; pp. 67-85.

22. Coralie, A. Durabilité des Miroirs Pour L'énergie Solaire à Concentration: Etude des Modes de Vieillissement. Ph.D. Thesis, Université Clermont Auvergne, Clermont Auvergne, France, 2018.

23. Guerguer, M.; Karim, M.; Naamane, S.; Edfouf, Z.; Raccurt, O. Degradation of solar glass mirrors paints at marine outdoor site. AIP Conf. Proc. 2018, 2033, 230004.

24. Guerguer, M.; Naamane, S.; Karim, M.; Bouaouine, H. Outdoor exposure testing of silvered-glass reflectors under marine environment. AIP Conf. Proc. 2019, 2126, 160003.

25. Girard, R.; Delord, C.; Disdier, A.; Raccurt, O. Critical constraints responsible to solar glass mirror degradation. Energy Procedia 2015, 69, 1519-1528. [CrossRef]

26. Rossi, S.; Fedel, M.; Deflorian, F.; Zanol, S. Influence of different colour pigments on the properties of powder deposited organic coatings. Mater. Des. 2013, 50, 332-341. [CrossRef]

27. Wyszecki, G.; Stiles, W.S. Colour Science; Concepts and Methods, Quantitative Data and Formulae, 2nd ed.; Wiley: New York, NY, USA, 2000.

28. ASTM E313-20. Standard Practice for Calculating Yellowness and Whiteness Indices from Instrumentally Measured Color Coordinates; ASTM: West Conshohocken, PA, USA, 2020.

29. Schütz, E.; Berger, F.; Dirckx, O.; Chambaudet, A. Study of degradation mechanisms of a paint coating during an artificial aging test. Polym. Degrad. Stab. 1999, 65, 123-130. [CrossRef]

30. Raccurt, O.; Delord, C.; Bouquet, C.; Couturier, R. Correlation between solar mirror degradation and colorimetric measurement of protective back layer. Energy Procedia 2014, 49, 1700-1707. [CrossRef]

31. Down, J.L. The Yellowing of Epoxy Resin Adhesives: Report on High-Intensity Light Aging. Stud. Conserv. 1986, 31, 159-170. [CrossRef]

32. Down, J.L. The yellowing of epoxy resin adhesives: Report on natural dark aging. Stud. Conserv. 1984, $29,63-76$.

33. Tennent, N.H. Clear and Pigmented Epoxy Resins for Stained Glass Conservation: Light Ageing Studies. Stud. Conserv. 1979, 24, 153-164.

34. Ginell, W.S.; Coffman, R. Epoxy resin-consolidated stone: Appearance change on aging. Stud. Conserv. 1998, 43, 242-248.

35. Allen, N.S.; Robinson, P.J.; White, N.J.; Swales, D.W. Photo-oxidative Stability of Electron Beam andUV Cured Acrylated Epoxy and Urethane Acrylate Resin Films. Polym. Degrad. Stab. 1987, 19, 147-160. [CrossRef] 